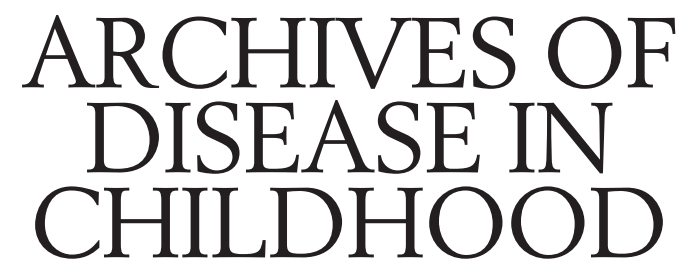

The Fournal of the Royal College of Paediatrics and Child Health

\title{
Annotations
}

\section{UK paediatric clinical research under threat}

We see clinical paediatric research in the UK as being under threat. Ultimately, this could affect the quality and nature of material submitted for publication. This annotation takes a brief look at the various pressures both old and new that face clinical paediatric research. By clinical research, we mean research on patients or groups of patients. We use the term to distinguish this from laboratory or 'test tube' research. As will be seen below, some of the factors that may have an adverse effect on the quantity of clinical research may have a positive effect on the amount of laboratory research.

Universities in England are funded, via the Higher Education Funding Council for England (HEFCE) to teach students and to do research. The purpose of the HEFCE's funding for research is to provide for the research infrastructure in universities, to form part of the dual support system whereby public funds for research are provided through funding councils and research councils, to enable universities to undertake collaborate research with industry, charities and others, and to cover most of the costs of basic research undertaken by universities. Universities are subject to a research assessment exercise (RAE), currently every five years. Similar conditions apply in Wales, Scotland, and Northern Ireland. The HEFCE allocates nearly all funds for research (around $95 \%$ ) by reference to research quality. The aim is to make the best possible use of public money by selectively funding the highest quality research. Ultimately it seems inevitable that research will be confined to a small number of selected 'premier league' universities that perform both teaching and research, the rest (more like a non-league team) only performing teaching. The pros and cons of the startling concept of studying medicine at an institution that performed no research is a separate topic in its own right, and is not something we will address here. In this paper, we focus on the effects of the $\mathrm{RAE}$ on clinical research in paediatrics in the UK.

\section{The university RAE}

Universities in England submitted their returns for the latest RAE in March 1996, and are collectively holding their breath awaiting the outcome, which will have a profound effect on their research funding for the next five years. Disciplines are allocated to RAE units of assessment. Medicine relates mainly to three units of assessment, 'hospital based clinical subjects' (this includes medicine, surgery, obstetrics, and paediatrics), 'community based clinical subjects' (for example general practice, psychiatry, public health), and 'clinical laboratory sciences' (for example pathology, radiology, medical genetics). For each unit of assessment, there is an assessment panel, comprised of experts from up and down the country. Each panel has the task of arriving at a quality assessment, which at the last exercise five years ago ranged from 1 (the lowest score) to 5 (the highest score).

\section{THE QUALITY SCORE}

The highest quality scores indicate that the majority of the research being done is of international standard. The main proxies for high quality research are research grant income and high quality peer reviewed journal research publications.

(1) Research grant income. Research council grant income, for example from the Medical Research Council (MRC), is especially highly valued, partly because it is so difficult to obtain, and partly because universities receive an additional $50 \%$ of the research grant as 'overheads'. In other words, if someone at the University of Edinburgh obtained a $£ 100000$ grant from the MRC, the University of Edinburgh would receive an additional $£ 50$ 000, a powerful incentive. There is an additional equally powerful 'knock-on' incentive; because research council grant income is so valuable both in direct financial terms and indirect financial terms (that is, the favourable effect on the RAE quality assessment), obtaining research council grants is very important for university promotions and chair appointments. Also important for the quality assessment is research grant income from peer reviewed charitable sources such as the Wellcome Trust, the Cancer Research Campaign, Birthright, Action Research, and others, as well as income from the National Health Service (NHS) Research and Development exercise. 
(2) Publication quality. In the present RAE, a proxy for publication quality is impact factor. Impact factors are ratios obtained from dividing the number of citations received by a journal in one year by the number of papers published in the two previous years. Thus, for example, the 1994 impact factor for the New England fournal of Medicine is 22.7. ' The Lancet had an impact factor of 17.3, and the British Medical fournal 4.4.

\section{THE VOLUME DRIVER}

In order to be declared as 'research active' in the RAE, university employees have to have published a minimum of four research papers during the period of assessment (that is, the previous four to five years).

THE RAE FUNDING CALCULATION

At the last RAE, for funding purposes the quality rating (on a scale of 1 to 5) minus 1 was multiplied by a volume measure in which a research active university funded and employed member of staff was weighted at 1.0, a research assistant or fellow was weighted as 0.1 , and a research student was weighted at 0.15 . By far the largest part of the volume measure (around 75\%) was accounted for by academic staff. The numbers of research active staff are frozen between RAEs, so that a research inactive member of staff penalises the university for the full five years between RAEs.

THE CULLYER MONIES

Formerly, teaching hospitals received special funding to offset the additional costs of teaching and research, known as SIFTR. In the future the ' $R$ ' element is being removed, and reallocated to hospitals that will competitively bid for research support. Exactly how this money will be distributed is uncertain, but it seems likely that there will be some sort of quality assessment that will take into account research income and publication quality. Although the most fierce pressures to improve research quality currently fall upon universities, it is clear that similar pressures will also affect research in the NHS.

MANY PUBLICATIONS NO LONGER 'COUNT' AS RESEARCH

For the purposes of the HEFCE RAE, clinical case reports, clinical reports of series of patients, review articles, editorials, and book chapters are not likely to count as research. Indeed, some British universities have taken the startling step of advising or even ordering staff to decline invitations to publish such material, on the grounds that it cannot be declared in the RAE (and is therefore no benefit to the institution). The bosom might swell with pride to be invited to contribute an annotation or review for the Archives, but it cannot be declared in the RAE, and all journal editors are likely to find it increasingly difficult to persuade academic staff to write review articles.

RESEARCH GRANT INCOME AS A DRIVER

Much of the major research grant income is going to support laboratory research, applications coming from existing sizeable research groups. Obtaining funding for high quality clinical research is increasingly challenging. Problems include the need to recruit adequate numbers of patients, obtaining funding for the cost of treatment, and having access to the infrastructure required to run large clinical trials, perform health economic assessments, measure quality of life and so on.

Another factor is so-called research contract income. If a university researcher seeks financial support for research from industry (for example a pharmaceutical company), the university requires that the industry source pays an additional overhead charge, which ranges from 50 to $150 \%$ of the research support. Income from industry is classed as research contract income, and universities are penalised if they fail fully to recover research contract overhead money. This is one of a number of factors that is driving pharmaceutical company support for research to other countries that offer cheaper ways of conducting, for example, clinical trials.

\section{Other obstacles to clinical research}

Cells and test tubes do not need referral from a fund holding general practitioner, performing chromatography does not usually require approval from 10-20 research ethics committees, and Southern blotting does not usually require large numbers of schoolchildren to miss several days of school in order to attend a hospital three bus rides away. The perception, rightly or wrongly, is that it is easier to perform and obtain funding for laboratory research than clinical research.

PRESTIGE

If one looks at applications for major research fellowships, applicants are far more likely to seek research training in laboratory research than clinical research. Reasons for this include the perception that laboratory research will offer better research training, and prestige. Working at the cutting edge of science in a molecular biology research team is probably more attractive than being one of many people involved in a multicentre controlled trial. More important, the former is far more likely to yield research data that can be published and form the basis for a higher degree (MD or PhD).

DIFFICULTIES IN ACADEMIC RECRUITMENT

There are numerous obstacles to academic recruitment. ${ }^{23}$ There are a number of financial disadvantages to an academic career (compared with working in the NHS), starting with the relative lack of financial help with house moving and relocation if one is employed by a university. There is likely to be considerably less time on-call, with a reduction in additional duty hour payments, and universities have for many years deliberately delayed the implementation of NHS salary awards, and for senior academic staff there is no potential for private practice income. Maybe more important, university posts in clinical training grades are all too often even more overloaded than equivalent registrar or senior registrar posts. It is still common to find academic posts in which the appointee has exactly the same full time duties as the NHS registrars/senior registrars, and the same need for clinical training, but with additional responsibilities for teaching, organising and marking examinations, and the expectation that first rate research will be performed simultaneously.

Calmanisation is the latest and possibly the greatest threat to academic recruitment. Medical research seems to have been very peripheral to the new approach to training, and it has been considered very much as an afterthought. One year for research will do little more than give a glimpse, and both clinical and laboratory research are likely to suffer. The arrangements for those who want to spend longer doing research are currently obscure to potential recruits, even if they may appear clear to Specialist Training Committee chairmen and postgraduate deans.

THREATS TO CLINICAL LECTURER POSTS

Clinical lecturer posts allow the appointee to continue clinical training while getting their first taste of research. For some this is the beginning of a lifelong academic career. For others it offers the opportunity to undertake research and develop teaching skills, before a final career in the NHS. Nationwide, however, universities are taking a 
close look at clinical lecturer posts, and if any survive close scrutiny (and it seems likely that many will not) then they are likely to be very different. The HEFCE RAE rears its head yet again. The problem is for the university funded (as opposed to the NHS funded) clinical lecturer posts. The difficulty is quite simply that very few incumbents are sufficiently established in their research careers to allow them to be declared as 'research active' at the RAE. Inability to declare university funded posts in the RAE results in a huge financial loss, and universities up and down the country are being sorely tempted to scrap these posts. Within the present structure where most lecturer posts are locked into clinical rotations, with heavy clinical commitments, it is almost inevitable that research productivity is low. In much the same way that those involved in implementing Calman training schemes do not have the support of research or research training as a priority, so universities in the future are likely to be less concerned with funding clinical training posts that offer little opportunity for research. The very first rung on the academic ladder looks set to disappear, and universities may be very tempted to replace some clinical lecturer posts with non-clinical lecturer posts, with the dual attractions that the appointee is likely to be doing laboratory research, and will not be distracted by clinical pressures. The proposed exclusion of clinical lecturer posts from some Calman training schemes would have the same effect as withdrawal of university funding; the posts would evaporate.

Many universities have coped with severe financial pressures by a policy of non-replacement of academic staff. Clinical training grades (that is, clinical lecturers) have usually been exempt from this policy, but with the massive 1996 university budget cuts even these posts are unlikely to be spared, particularly because of their poor performance in the RAE.

Other types of recruitment into academic careers are under threat, for example due to withdrawal of MRC funding for intercalated BSc students, ${ }^{4}$ but these pressures will have an equal affect on clinical and laboratory research.

CHARITY FUNDED RESEARCH REGISTRAR POSTS

A number of medical charities have in the past funded research registrar posts. These have provided an extra pair of hands to help run the clinical service, and to do research.
However most charities are phasing these out, for two reasons. One is a preference for research money to be more clearly focused on research, notably basic science laboratory research. Another is the feeling that it is the job of the NHS to pay for the running of the clinical service. The loss of these posts has in turn caused a large drop in the number of posts available for clinical research.

PAEDIATRICS AS A SMALL AND ISOLATED SPECIALTY

We are told that as viewed by the HEFCE RAE assessment panel, academic paediatrics performs poorly compared with, for example, adult medicine. Academic paediatrics is disadvantaged by the relatively small size of the academic departments in the UK, their fragmentation from each other and from adult medicine, and (for those that are located in stand-alone children's hospitals) the geographical isolation from biomedical research on the university campus. Better integration will be needed if paediatric research (both clinical and laboratory) is to flourish in Britain.

\section{Conclusions}

The drive to improve the quality of research will leave a number of universities as casualties. Small and isolated research groups are especially under threat, posing difficulties for paediatrics because of its relatively small size in the UK. The way the RAE operates, along with a number of other factors operating simultaneously, and coupled with a general decline in clinical research, ${ }^{5}$ threaten clinical paediatric clinical research in the UK. One anxiety is that this comes at the very time that professionals, purchasers and the public are demanding more 'evidence-based' clinical practice, a goal that will be hard to achieve if clinical research is allowed to atrophy.

ANONYMOUS

\footnotetext{
1 Garfield E. How can impact factors be improved? BMf 1996;313:411-3. 2 Beecham L. Disincentives to an academic career spelt out. BMF 1996;312: 1543

3 Dean M. British medical academic work faces 'triple whammy'. Lancet 1996;347:1685.

4 Attwell D, Boyd R. Withdrawal of Medical Research Council funding for intercalated BSc students. Lancet 1996;348:198.

5 Smith R. Does Britain need an academy of medicine? BMF 1996;312:1374-5.
}

\section{Paediatric nutrition as a new subspecialty: is the time right?}

Scientific interest in nutrition in early life preceded the formal development of paediatrics. Building on biochemical studies of the 18 th century, ${ }^{1}$ Franz Simon underpinned a rational, scientific basis for infant feeding with his landmark work in $1838,{ }^{2}$ when the word 'paediatrics' had not even entered the English language. ${ }^{3}$ This was 20 years before the first chair of paediatrics in the US and a century before paediatric chairs were created in Britain (1930s). By then, the field of paediatric nutrition had already passed many major milestones, ${ }^{4}$ for instance the scientific understanding that led to prevention and treatment of infantile scurvy and rickets. ${ }^{56}$ In 1940 the editors of Holt's Diseases of Infancy and Childhood (11th edition) stated 'Nutrition in its broadest sense is the most important branch of paediatrics'. ${ }^{7}$ Given the extraordinary scientific effort and interest over the past two centuries, it is paradoxical that nutrition has never emerged as an independent paediatric specialty, when other areas of much more recent focus have done so.

Why should this be so? Firstly, the intensive interest in nutrition largely solved the earlier concerns. With the exception of iron deficiency anaemia, primary nutritional deficiency diseases are now uncommon in the West. Secondly, other specialties have evolved partly from the need to master specialised techniques (for example cardiac catheterisation); yet, until recently there have been few such techniques in clinical nutrition. Thirdly, medical specialties have been based traditionally on organ systems, a 